\title{
Factors Associated with Short-Term Seizure Recurrence in Extratemporal Epilepsy Surgery
}

\author{
Aisel Santos Santos ${ }^{1 *}$, Lilia María Morales Chacón ${ }^{2}$, Narjara Castillo Ferrán ${ }^{1}$, Manuel Ulises Dearriba Romanidy ${ }^{1}$, Liana Portela Hernández \\ 1, Leidy García Morales ${ }^{1}$, Henry Freeman Guillén ${ }^{1}$, Vicente Rio Vázquez ${ }^{1}$, Lisbeth Fernández Gonzalez ${ }^{3}$, Juan Mario Junco Rodríguez \\ ${ }^{4}$, Calixto Machado ${ }^{1}$, Brandon Brock ${ }^{5}$
}

${ }^{1}$ Intituto Nacional de Neurología y Neurocirugía (INN). La Habana Cuba

${ }^{2}$ Centro Internacional de Restauración Neurológica (CIREN). La Habana, Cuba.

${ }^{3}$ Instituto Nacional de Higiene, epidemiologia y microbiología (INHEM)

${ }^{4}$ Instituto Pedro Kouri (IPK). La Habana, Cuba.

${ }^{5}$ Texas Woman's University, Department of Ph.D. Studies, Denton, TX, USA

*Corresponding Author: Santos Santos Aise, Intituto Nacional de Neurología y Neurocirugía (INN). La Habana Cuba,

Received date: July 14, 2021; Accepted date: July 29, 2021; Published date: August 04, 2021

Citation: Aisel S. Santos., Morales Chacón LM., Narjara C. Ferrán., Dearriba Romanidy MU., Liana P. Hernández., et all. (2021) Factors Associated with Short-Term Seizure Recurrence in Extratemporal Epilepsy Surgery. J. Neuroscience and Neurological Surgery. 9(3); DOI:10.31579/2578-8868/196

Copyrights: () 2021 Santos Santos Aise, This is an open-access article distributed under the terms of The Creative Commons Attribution License, which permits unrestricted use, distribution, and reproduction in any medium, provided the original author and source are credited

\begin{abstract}
:
Introduction: Drug-resistant extratemporal epilepsy is the second cause of referral to epilepsy surgery. Objectives: To identify factors associated with short-term seizure recurrence following extratemporal epilepsy surgery.

Materials and Methods: We performed a retrospective study of 19 consecutive patients who underwent surgery for drug-resistant extratemporal epilepsy at the National Institute of Neurology and Neurosurgery of Havana, Cuba, from September 2014 to October 2019. All patients had at least one year of postoperative follow-up. Fisher's exact test was used to search for an association between dichotomous variables. A value of $\mathrm{p} \leq 0.05$ was considered significant.

Results: After one year of follow-up, seizure freedom reached 31.6\% (Engel I) and 36.8\% showed significant improvement in the number of seizures (Engel II). The frontal location $(\mathrm{p}=0.046)$ and incomplete resection of the epileptogenic zone $(\mathrm{p}=0.017)$, bilateral interictal discharges on the preoperative electroencephalogram (EEG) $(\mathrm{p}=0.017)$, the presence of epileptiform discharges on the postsurgical EEG $(\mathrm{p}=0.001)$, and the occurrence of seizures after the sixth month of surgery $(\mathrm{p}=0.001)$, were associated with seizures recurrence.

Conclusions: After one year, $31.6 \%$ of patients operated on for extratemporal epilepsy were seizure-free. The incomplete resection of the epileptogenic zone and the presence of epileptogenic discharges in the postsurgical EEG, and the presence of seizures after the sixth month of surgery were the most significant factors of seizure recurrence.
\end{abstract}

Keywords: extratemporal epilepsy surgery; prognosis, predictors

\section{INTRODUCTION}

Estimations consider that at least 50 million people live with epilepsy worldwide, 5 million of whom are from the "Americas".[1] Close to onethird of cases do not respond to pharmacological treatment, and of these, between 10 and $15 \%$ are candidates for surgery. [2]

$20 \%$ of patients who underwent surgery showed the extratemporal location, predominantly in the frontal lobe. [3, 4] The outcomes of different series of extratemporal surgery are varied. West et al. [5] found
30 to $50 \%$ of seizure freedom (Engel I), Morales et al. [6], in Cuba, found $52.6 \%$ of patients in Engel I during the first year and $41.1 \%$ after two years of follow-up. In the literature consulted, Jehi et al, [7] reported between 13 and $80 \%$ of seizure freedom after frontal lobe surgery. These results clearly show the superiority of surgery over the medical treatment alternative. Even so, only one percent of the cases that could probably benefit from this procedure are referred for presurgical evaluation. With 
an average of 20 years or more from the onset of their disease, on the other hand, about half of the patients who undergo epilepsy surgery in the world continue with seizures $[8,9]$ so it is of utmost importance to better predict the postoperative prognosis. The literature describes different clinical, surgical, electrophysiological, and imaging variables, which behave as prognostic factors. [5]

In Cuba, epilepsy surgery is also an underused option and patients arrive at the presurgical evaluation with more than 20 years of diagnosis of their disease. [6] This article aims to show, for the first time, the extratemporal epilepsy surgical series of the National Institute of Neurology and Neurosurgery of Havana, Cuba, to identify factors associated with shortterm seizure recurrence following extratemporal epilepsy surgery, facilitating thus the early and most adequate selection of candidates for surgery.

\section{MATERIALS AND METHODS}

We performed a retrospective study of 19 consecutive patients operated for drug-resistant extratemporal epilepsy at the National Institute of Neurology and Neurosurgery of Havana from September 2014 to October 2019, with a comprehensive epilepsy surgery program. All the patients had at least one year post-surgery follow-up.

The information was gathered from the patients' medical records. The variables evaluated as potential predictors were: a) age at diagnosis of epilepsy and at the time of surgery; b) medical history (initial precipitating factors related to epilepsy in the prenatal, perinatal, or postnatal stage); c) seizure semiology and monthly frequency; d) preoperative electroencephalogram (interictal EEG, ictal onset) and neuroimaging findings; e) type of surgery; f) results of intraoperative electrocorticography (ECoG) before and after surgery; g) anatomopathological studies; h) postoperative electroencephalogram (EEG) and magnetic resonance imaging (MRI) as well as i) the occurrence of seizures before and after six months. [4-7, 9]

Preoperative evaluation $[6,10]$

All patients were evaluated in a non-invasive way, with prolonged videoEEG monitoring and electrodes placed according to the international 1020 system and additional electrodes depending on the topography of the epileptogenic zone (EZ). The interictal epileptiform activity was classified as ipsilateral whenever it was consistent with the ictal onset or bilateral zone when it occurred in both hemispheres. 1.5T and/or 3T highfield MRI with epilepsy protocol was performed in all patients and interictal and ictal single-photon emission tomography (SPECT) was coregistered to MRI in patients with normal MRI.

\section{Surgical Procedure}

Depending on the type of surgical procedure used, these were classified as resection, disconnection, or a combination of both. [5]

A pre-surgical ECoG was performed and patterns were classified as specific, according to criteria based on Boonyapisit 2003: a) isolated spikes, amplitude> $200 \mathrm{mV}$; b) bursts duration $>0.5 \mathrm{~s}$, amplitude $>200 \mu \mathrm{V}$, frequency $\pm 7-10 \mathrm{~Hz}$, regular firing; c) paroxysmal fast: burst duration $>0.5 \mathrm{~s}$, frequency $>10 \mathrm{~Hz}$, regular firing and d)runs of slow repetitive spikes: duration $>0.5 \mathrm{~s}$, amplitude $>200 \mu \mathrm{V}$, frequency $<7$ $\mathrm{Hz}$, regular firing; and non-specific. [11] After a postsurgical procedure ECoG, it was analyzed whether the pattern disappeared, changed (a decrease of $50 \%$ or more of the epileptiform discharges per minute concerning the presurgical study), or whether it remained unchanged. [6]

\section{Postoperative prognosis and follow-up [10]}

Anatomopathological studies of the samples were performed and classified as focal cortical dysplasia (FCD) according to the ILAE classification, (12) descriptive or unspecified.

Six months after surgery, an MRI was performed. It was evaluated whether the resection of the estimated epileptogenic zone (EZ) was complete or incomplete. It was considered a complete resection when it was possible to completely resect the identified ictal area and the cortex that showed epileptiform activity on EcoG. In patients in whom the MRI showed a lesion, a total resection of said lesion guided by ECoG with the absence of epileptiform activity at the edges of the resection. An EEG was also performed to analyze the topography and the presence or absence of epileptiform activity. After the first year, the cases were classified according to the Engel Class Outcome System, Engle I was considered a good prognosis (seizure freedom) and Engel II to IV a recurrence of seizures, short-term follow-up (one year). [4,7]

\section{Statistical analysis}

The information was stored in a Microsoft Excel database, and its analysis was carried out in the SPSS system version 20.1.

The categorical variables were presented in the form of frequencies and percentages. Fisher's Exact Test was used to associate the dichotomous variables. A value of $\mathrm{p} \leq 0.05$ was considered significant.

\section{Ethical aspects}

This research was approved by the Institute of Neurology and Neurosurgery Ethics Committee, which acted following the current laws and regulations issued by the Ministry of Public Health of Cuba (MINSAP) and follows the principles outlined in the Declaration of Helsinki of the World Medical Association for Human Medical Research. RESULTS

Of the 19 patients studied, 16 were male and three females, ranging in age between 13 and 34 years. Most of them (57.9\%) were distributed in the age group of 16 to 30 years.

After one year of follow-up, $31.6 \%$ of the patients were seizure-free (Engel I), seven patients $(36.8 \%)$ presented significant seizure improvement (Engel II). The rest were distributed between Engel III $(21.1 \%)$ and Engel IV (10.5\%).

It was observed a predominance of patients with over 15 years from the time of their epilepsy diagnosis until surgery with 13 patients $(68.4 \%), 8$ of which $(42.1 \%)$, with more than 20 years of evolution of their disease. (Table 1) 


\begin{tabular}{|c|c|c|c|c|c|c|c|c|}
\hline \multirow{3}{*}{ Variables } & \multirow{3}{*}{ Categories } & \multicolumn{4}{|c|}{ Engel class } & \multirow{2}{*}{\multicolumn{2}{|c|}{$\begin{array}{l}\text { Total } \\
\mathbf{n}=19\end{array}$}} & \multirow{3}{*}{$\mathbf{P}$} \\
\hline & & \multicolumn{2}{|c|}{$\begin{array}{c}I \\
n=6\end{array}$} & \multicolumn{2}{|c|}{$\begin{array}{l}\text { II-IV } \\
n=13\end{array}$} & & & \\
\hline & & $\mathbf{N}^{\circ}$ & $\%$ & $\mathbf{N}^{\circ}$ & $\%$ & $\mathbf{N}^{\circ}$ & $\%$ & \\
\hline \multirow{2}{*}{$\begin{array}{l}\text { Time between diagnosis of } \\
\text { epilepsy and surgery }\end{array}$} & $0-15$ years & 3 & 50.0 & 3 & 23.1 & 6 & 31.6 & \multirow{2}{*}{0.257} \\
\hline & Over 15 years & 3 & 50.0 & 10 & 76.9 & 13 & 68.4 & \\
\hline \multirow[t]{2}{*}{ Type of seizures } & $\begin{array}{l}\text { Focal onset with impaired } \\
\text { awareness }\end{array}$ & 4 & 66.7 & 12 & 92.3 & 16 & 84.2 & \multirow[t]{2}{*}{0.222} \\
\hline & Focal onset aware & 2 & 33.3 & 1 & .7 .7 & 3 & 15.8 & \\
\hline \multirow{2}{*}{ Bilateral Tonic-clonicseizures } & yes & 6 & 100 & 10 & 76.9 & 16 & 84.2 & \multirow{2}{*}{0.295} \\
\hline & No & 0 & 0 & 3 & 23.1 & 3 & 15.8 & \\
\hline \multirow{2}{*}{ Seizures per month } & 20 years or less & 4 & 66.7 & 4 & 30.8 & 8 & 42.1 & \multirow{2}{*}{0.166} \\
\hline & More than 20 years & 2 & 33.3 & 9 & 69.2 & 11 & 57.9 & \\
\hline \multirow{2}{*}{ Medical history } & Yes & 0 & 0 & 6 & 46.2 & 6 & 31.6 & \multirow{2}{*}{0.063} \\
\hline & No & 6 & 100 & 7 & 53.8 & 13 & 68.4 & \\
\hline \multirow{2}{*}{ Presurgical EEG (ictalonsetzone) } & Frontal & 2 & 33.3 & 11 & 84.6 & 13 & 68.4 & \multirow{2}{*}{0.046} \\
\hline & Posterior region & 4 & 33.3 & 2 & 15.4 & 6 & 31.6 & \\
\hline \multirow{2}{*}{ Interictalepileptiformactivity } & Ipsilateral & 6 & 100 & 5 & 38.5 & 11 & 57.9 & \multirow{2}{*}{0.017} \\
\hline & Bilateral & 0 & 0 & 8 & 61.5 & 8 & 42.1 & \\
\hline \multirow{2}{*}{ Presurgical MRI } & Lesional & 5 & 83.3 & 6 & 46.2 & 11 & 57.9 & \multirow{2}{*}{0.153} \\
\hline & No lesional & 1 & 16.6 & 7 & 53.8 & 8 & 42.1 & \\
\hline \multirow{2}{*}{ Epileptogenic zone eloquent area } & Yes & 2 & 33.3 & 7 & 53.8 & 9 & 47.4 & \multirow[t]{2}{*}{0.370} \\
\hline & No & 4 & 66.7 & 6 & 46.2 & 10 & 52.6 & \\
\hline
\end{tabular}

MRI: Magnetic Resonance Imaging, EEG: electroencephalogram

Table 1: Presurgical variables and their relationship with the short-term postsurgical clinical course. INN, 2014- 2019.

Focal-onset seizures with impaired awareness were the most frequent, 16 patients $(84.2 \%)$; likewise, 16 presented seizures with evolution to a bilateral tonic-clonic at some point in their disease. $57.9 \%$ of the cases presented more than 20 monthly seizures before surgery. None of these variables was statistically associated with postoperative evolution.

Patients with a history such as hypoxia and head trauma $(6$ patients = $31.6 \%$ ) were distributed on the Engel II scale upwards.

The ictal onset in the frontal lobe predominated, 13 patients (68.4\%), 11 presented recurrence of seizures. Both had a statistical association in the short term.
Interictal epileptiform activity occurred bilaterally in 8 patients $(42.1 \%)$, all of them presented recurrence of seizures after surgery, which was statistically associated $(\mathrm{p}=0.017)$.

On MRI, $57.9 \%$ of the patients presented lesions, primarily distributed between Engel I and II. Six non-lesional patients underwent ictal and interictal SPECT and subsequent co-registration with MRI. The focal hyperperfusion found in all of them was consistent with the rest of the evaluation.

Electrocorticography was performed in 16 patients (84.2\%), who predominantly were classified as Engel I and Engel II, with classic patterns in the presurgical ECoG and the prevalence of the pattern of the repetitive spikes $(68.4 \%)$. Table 2.

\begin{tabular}{|c|c|c|c|c|c|c|c|c|}
\hline \multirow{3}{*}{ Variables } & \multirow{3}{*}{ Categories } & \multicolumn{4}{|c|}{ Engel class } & \multirow{2}{*}{\multicolumn{2}{|c|}{$\begin{array}{l}\text { Total } \\
\mathrm{n}=19\end{array}$}} & \multirow{3}{*}{$\mathbf{P}$} \\
\hline & & \multicolumn{2}{|c|}{$\begin{array}{c}I \\
n=6\end{array}$} & \multicolumn{2}{|c|}{$\underset{n=13}{\text { II }}$} & & & \\
\hline & & $\mathbf{N}^{\circ}$ & $\%$ & $\mathbf{N}^{\circ}$ & $\%$ & $\mathbf{N}^{\circ}$ & $\%$ & \\
\hline \multirow{2}{*}{$\begin{array}{l}\text { Epileptiform } \\
\text { activity Pre-surgical } \\
\text { ECoG }\end{array}$} & Classic patron & 6 & 100 & 10 & 76.9 & 16 & 84.2 & \multirow[b]{2}{*}{0.295} \\
\hline & Not performed & 0 & 0 & 3 & 23.1 & 3 & 15.8 & \\
\hline \multirow[b]{2}{*}{$\begin{array}{l}\text { Surgicalprocedureu } \\
\text { sed }\end{array}$} & Resective & 5 & 83.3 & 4 & 30.7 & 9 & 47.4 & \multirow[b]{2}{*}{0.050} \\
\hline & $\begin{array}{c}\text { Desconnect/ } \\
\text { Combined }\end{array}$ & 1 & 16.6 & 9 & 69.2 & 10 & 52.6 & \\
\hline \multirow{2}{*}{$\begin{array}{l}\text { Epileptiform } \\
\text { activity post- } \\
\text { surgical ECoG }\end{array}$} & Disappeared & 4 & 66.7 & 4 & 30.7 & 8 & 42.1 & \multirow[b]{2}{*}{0.304} \\
\hline & Was modified & 2 & 33.3 & 6 & 46.2 & 8 & 42.1 & \\
\hline
\end{tabular}

ECoG:Electrocorticography,

Table 2: Intraoperative variables and their relationship with the short-term postsurgical clinical course. INN, $2014-2019$. 
Resective surgical techniques were given preference, 9 patients for a 47.4 $\%$, prevailing the ECoG-guided lesionectomy, six patients $(31.6 \%)$, and subtotal lobar resections. Six patients $(31.6 \%)$ benefited from the combination of resective and disconnective techniques. Disconnection surgery was used in only four patients: anterior corpus callosotomy in three patients and multiple subpial transections (MST) in one patient with $\mathrm{ZE}$ in the primary motor area.

The postsurgical ECoG showed that the presurgical pattern disappeared in 8 patients $(42.1 \%)$, and in other 8 patients it was modified.
The most frequent anatomopathological diagnosis was the focal cortical dysplasia type IA with six patients $(31.6 \%)$, distributed across Engel classes II to IV, followed by FCD IIA. Out of those that evolved without seizures after surgery (Engel I), two patients were classified as FCD type III B (associated with tumors) and two patients as descriptive results.

In the postsurgical EEG, 11 patients $(57.9 \%)$ presented interictal epileptiform discharges (IED), all presented recurrence of seizures after surgery (Engel II-IV), which was statistically significant $(\mathrm{p}=0.001)$. Table 3

\begin{tabular}{|c|c|c|c|c|c|c|c|c|}
\hline \multirow{3}{*}{ Variables } & \multirow{3}{*}{ Categories } & \multicolumn{4}{|c|}{ Engel class } & \multirow{2}{*}{\multicolumn{2}{|c|}{$\begin{array}{l}\text { Total } \\
n=19\end{array}$}} & \multirow{3}{*}{$\mathbf{P}$} \\
\hline & & \multicolumn{2}{|c|}{$\underset{n=6}{I}$} & \multicolumn{2}{|c|}{$\begin{array}{l}\text { II-IV } \\
n=13\end{array}$} & & & \\
\hline & & $\mathbf{N}^{\circ}$ & $\%$ & $\mathbf{N}^{\circ}$ & $\%$ & $\mathbf{N}^{\circ}$ & $\%$ & \\
\hline \multirow{2}{*}{$\begin{array}{l}\text { Postoperative } \\
\text { (IED) }\end{array}$} & Yes & 0 & 0 & 11 & 84.6 & 11 & 57.9 & \multirow{2}{*}{0.001} \\
\hline & No & 6 & 100 & 2 & 15.4 & 8 & 42.1 & \\
\hline \multirow{2}{*}{ Postoperative MRI } & Complete resection & 4 & 66.7 & 1 & 7.7 & 5 & 26.3 & \multirow{2}{*}{0.017} \\
\hline & Incomplete resection & 2 & 33.3 & 12 & 92.3 & 14 & 73.7 & \\
\hline \multirow{2}{*}{$\begin{array}{l}\text { Seizures in the first } 6 \\
\text { months after surgery }\end{array}$} & Yes & 3 & 50.0 & 11 & 84.6 & 14 & 73.7 & \multirow[b]{2}{*}{0.151} \\
\hline & No & 3 & 50.0 & 2 & 15.4 & 5 & 26.3 & \\
\hline \multirow{2}{*}{$\begin{array}{l}\text { Seizures after } 6 \\
\text { months from date of } \\
\text { surgery }\end{array}$} & Yes & 1 & 14.2 & 13 & 100 & 14 & 73.7 & \multirow[b]{2}{*}{0.001} \\
\hline & No & 5 & 83.3 & 0 & 0 & 5 & 26.3 & \\
\hline
\end{tabular}

EID: Epileptiform Interictal Discharges

Table 3: Postsurgical follow-up variables and their relationship with the short-term postsurgical clinical course. INN, $2014-2019$.

Patients with incomplete resection of the EZ (73.7\%) predominated in class II or higher of the Engel scale (seizure recurrence), finding a statistical association between these variables $(\mathrm{p}=0.017)$.

Of the 14 patients who presented seizures six months after surgery, 13 evolved from Engel II to Engel IV, which was statistically significant (p $=0.001$ ).

Regarding the postoperative complications, the evolution was very favorable, with a low rate of complications related to the surgical procedure in 4 patients $(21.1 \%)$, a cingulate infarction, 2 cerebrospinal fluid fistulas, and an epidural hematoma.

\section{DISCUSSION}

In the present research, most cases were male, and the prevailing age group that of 16 to 30 years. Other studies show similar data, such as one that was carried out in China [13] with 82 patients operated on for frontal lobe epilepsy, male sex predominated (59.8\%), and the mean age was 19.1 years. Similarly, in a meta-analysis carried out in Cincinnati, USA, with 2028 patients, the male sex predominates $(54.3 \%)$, and the mean age is $10.24 \pm 1.11$ years.[14] Similar results were found in the Cuban series of Morales et al.[6] with 55\% male predominance and a mean age of $24.1 \pm$ 10.1 (ranging 5 - 47 years).

The 2019 Cochrane review, [5] reports 30 to 50\% seizure freedom after extratemporal epilepsy surgery. In another investigation of frontal lobe surgery, [4] seizure freedom is obtained in $45 \%, 34 \%, 26 \%, 20 \%$ and $14 \%$ at the end of the $1 \mathrm{st}, 2 \mathrm{nd}, 3 \mathrm{rd}$, 4th and 5th years respectively after the surgery. Morales et al. [6], in Cuba, find $52.6 \%$ of the patients in Engel I in the 1 st year and $41.1 \%$ after a two-year follow-up.

The authors believe that the results of the present study, are related to the characteristics of the sample, the predominance of patients with nonlesional MRI, incomplete resection coinciding with eloquent areas, the presence of focal cortical dysplasia type IA as etiology, and the delay between the diagnosis of epilepsy and surgery. Nevertheless, after surgery, most of the patients showed a significant reduction in the number of seizures per month.

In the current study, patients with a medical record had a less favorable Engel classification, similar to Mariani V et al. [15]. Conversely, Sun et al. [16] describe that $33.6 \%$ have a positive history, most of them in the Engel I class.

In most patients in the present study, the condition evolved 15 years or more until the time of surgery. In other investigations performed about frontal lobe epilepsy surgery, more than $60 \%$ of cases remain seizure-free when the surgery was conducted in the first five years after the onset of the disease, but, when operated after that period, only 30\% improve clinically. The difference is more remarkable in patients with non-lesional frontal epilepsy, with $80 \%$ of seizure freedom with early treatment and only $10 \%$ with late treatment. [17] In their series in Cuba, Morales et al. [6] found that $86.9 \%$ had had the disease for more than five years.

Simasathien et al. [18] conclude that surgery in patients under 18 years of age and with less than five years of disease evolution are factors statistically related to a good postsurgical prognosis.

It is estimated that only $1 \%$ of patients who could benefit from surgery are referred for evaluation, and this usually occurs an average of 20 years after the onset of the disease. $[19,20]$

The most important modifiable factor described in several studies $[4,5$, $7,9,21-24]$ is the time elapsed between the diagnosis of epilepsy and surgery. If this factor is acted upon, better results will be obtained.

In one study carried out in China, it was observed that $61.8 \%$ presented lesions on MRI, and there is a correlation between this parameter and a better evolution of seizures after surgery. [13] Similar to what was found in the present study. Several authors, in turn, identified this factor as a predictor of good prognosis in extratemporal surgery. $[4,5,16,21,25-$ 29] 
The use of intraoperative electrocorticography in our environment has become increasingly important to delimit the resection edges and is related to the best results of the present research. Studies with ECoG offer more excellent coverage of areas of the cortex surface and allow spatial contiguity in detecting the ictal onset and its immediate propagation, the complete resection guided by ECoG of the cortical area that presents a FCD pattern, is a predictor of an excellent postsurgical prognosis detected by Morales et al. [6] in Cuba and other authors.[16, 30-32]

There was a statistical association between incomplete resection of the EZ and the recurrence of postsurgical seizures in the current investigation. Several authors describe the complete resection of the epileptogenic area as a predictor of a good prognosis. [5, 16, 21,30, 33-35] The Cochrane Review 2019, [5] and Chen et al., [36] concluded that incomplete resection is highly associated with a poor prognosis after surgery.

In the present study, FCD types IA and IIA were the most frequent anatomopathological diagnoses. In a meta-analysis [36] carried out with 48 studies on surgery for focal cortical dysplasia, it was determined that FCD type I was a significant predictor of recurrence, and type IIB was related to seizure control. Another study similar to the previous one conducted on parietal epilepsy surgery [37] found that the best postsurgical outcome is associated with epilepsy-related tumors, not with MCD (malformation of cortical development) and vascular malformations. In Cuba, Morales et al. [6] find $61.1 \%$ of MCD, with a predominance of FCD types I and II.

Some authors [21,38] identify the presence of epileptiform interictal discharges (EID) in the postsurgical EEG as a predictor of seizure recurrence, as in the present study, where a statistical association between these two variables was obtained.

Different mechanisms are identified for early recurrence, before six months, and late recurrence after six months onwards.

It is known that almost half of those operated on for extratemporal epilepsy recur after 2 to 6 months (early), which is related to incomplete resection of the epileptogenic zone, diffuse or poorly localized EZ. [39] However, after 6 months to several years, late recurrence is consistently seen in patients in all studies whose surgery was successful but who have developed new "epileptic foci" by secondary epileptogenesis mechanisms.

Several studies support the role of neuroinflammation and the complement system in epileptogenesis, the IL-1 receptor type II gene and IL-8 genes, among other markers, are expressed in different ways in patients who recur late. [36]

\section{Limitations of the study}

A small sample that reduces the possibility of generalizing the results from the statistical point of view.

\section{CONCLUSIONS}

The frontal location of the epileptogenic zone and its incomplete resection, the bilateral interictal activity in the presurgical EEG, interictal epileptiform discharges in the postsurgical electroencephalogram, and the presence of seizures after the sixth month after surgery was statistically associated with seizure recurrence.
A favorable evolution was obtained in more than half of the cases, grouped into the Engel classes I and II.

\section{REFERENCES}

1. Serratosa J, Garamendi I,Agundez M, Valle E, Galbarriatu L,García-Ribes A, et al. Epilepsias. Neurología. 6ta ed2018. p. 359-412.

2. Covanis A, Guekht A, Li S, Secco M, Shakir R, Perucca E. From global campaign to global commitment: The World Health Assembly's Resolution on epilepsy. Epilepsia 2015 Nov; 56(11):1651-1657.

3. Mercadé J M, Sancho J, Mauri J A, López F J, X. S. Guias diagnósticas y terapeuticas de la Sociedad española de neurologia 2012. In: Neurologia Sd, editor.: Ediciones Sen; 2012.

4. Samuel P, Menon R, Chandran A, Thomas S, Vilanilam G, Abraham M, et al. Seizure outcome and its predictors after frontal lobe epilepsy surgery. Acta Neurol Scand. 2019 Oct; 140(4):259-267.

5. West S, Nevitt SJ, Cotton J, Gandhi S, Weston J, Sudan A, Ramirez R, Newton R. Surgery for epilepsy. Cochrane Database of Systematic Reviews. 2019 Jun; 6: 1-205.. Art. No.: CD0105.

6. Morales Chacón L M, González González J, Quintanal Cordero N, Ríos M, Dearriba Romanidy M, Bender del Busto J E, et al.Presurgical Assessment and Surgical Treatment in Extra Temporal Lobe Epilepsy: A National Comprehensive Epilepsy Surgery Program in Cuba. Clin Surg 2019;4 (2546).

7. Jehi L, Najm I, Bingaman W, Dinner D, Widdess-Walsh P, Lüders H. Surgical outcome and prognostic factors of frontal lobe epilepsy surgery. Brain. 2007;130(2):574-584.

8. Jehi L, Jett N. Not all that glitters is gold: A guide to surgical trials in epilepsy. Epilepsia Open, 1(1):22-36, 2016.

9. Jehi L, Yardi R, Chagin K, Tassi L, Lo Russo G, Cendes F. et al. Development and validation of nomograms to provide individualised predictions of seizure outcomes after epilepsy surgery: a retrospective analysis. The Lancet Neurol 2015 mar;14(3): 283-290.

10. Bender del Busto J, González Judith. Evaluación clínica pre y post quirúrgica. En: Morales Chacón L. lineamientos para el tratamiento de las Epilepsias farmacorresistentes Cuba. Editorial Ciencias Médicas 2017: 18-31.

11. Boonyapisit K, Najm I, Klem G, Ying Z, Burrier C, LaPresto E, et al. Epileptogenicity of Focal Malformations Due to Abnormal Cortical Development: Direct Electrocorticographic-Histopathologic Correlations. Epilepsia 2003, 44(1):69-76.

12. Blümcke I, Thom M, Aronica E, Armstrong DD, Vinters HV, Palmini A, et al. The clinicopathologic spectrum of focal cortical dysplasias: a consensus classification proposed by an adhoc Task Force of the ILAE Diagnostic Methods Commission. Epilepsia. 2011;52(1):158-174.

13. $\mathrm{Xu} \mathrm{C}, \mathrm{Yu} \mathrm{T}$, Zhan G. Prognostic Factors and Longitudinal Change in Long-Term Outcome of Frontal Lobe Epilepsy Surgery. World Neurosurgery 2019 Jan; 121: 32-38.

14. Giridharan N, Horn P S, Greiner HM, Holland K D, Mangano F T, Arya R. Acute postoperative seizures as predictors of 
seizure outcomes after epilepsy surgery. Epilepsy Research. 2016;127:119-125.

15. Mariani V, Revay M, D’Orio P, Rizzi M, Pelliccia V, Nichelatti $M$, et al.Prognostic factors of postoperative seizure outcome in patients with temporal lobe epilepsy and normal magnetic resonance imaging. Journal of Neurology 2019 Sept; 266(9):2144-2156.

16. Sun Y, Wang X, Che N, Qin H, Liu S, Wu X, et al. Clinical characteristics and epilepsy outcomes following surgery caused by focal cortical dysplasia (type IIa) in 110 adult epileptic patients. Experimental and therapeutic medicine 2017 May; 13 (5): 2225-2234.

17. Jehi L. Neurology's Silent Killer: Drug-Resistant Epilepsy. Epilepsy Currents. 2016 16; (4) :232-233.

18. Simasathien T, Vadera S, Najm I, Gupta A, Bingaman W, Lara Jehi L. Improved Outcomes with Earlier Surgery for Intractable Frontal Lobe Epilepsy. ANN NEUROL. 2013;73:646-654.

19. Yeoun Yoo L, Panov F. Identification and Treatment of DrugResistant Epilepsy. Continuum (MinneapMinn). 2019;25(2):362-380.

20. Jehi L, Mathern GW. Who's responsible to refer for epilepsy surgery?We all are! Neurology. 2015;84(2):112-113.

21. Malmgren K, Edelvik A. Long-term outcomes of surgical treatment for epilepsy in adults with regard to seizures, antiepileptic drug treatment and employment. Seizure. 2017 Jan;44:217-224.

22. Ramantani G, Stathi A, Brandt A, Strobl K, Schubert-Bast S, Wiegand G, et al. Posterior cortex epilepsy surgery in childhood and adolescence: Predictors of long-termseizure outcome. Epilepsia 2017 Jan; 58(3):412-419.

23. D' Orio P, Pelliccia, V, Gozzo F, Cardinale F, Castana L, Russo G, et al. Epilepsy surgery in patients older than 50 years: effectiveness, safety, and predictors of outcome. Seizure. 2017 Aug;50:60-66.

24. Lamberink H, Otte W, Geerts A, Pavlovic M, Ramos-Lizana J, Marson A, et al. Individualised prediction model of seizure recurrence and long-term outcomes after withdrawal of antiepileptic drugs in seizure-free patients: a systematic review and individual participant data meta-analysis. Lancet Neurol 2017; 16: 523-531.

25. Jehi L, O’Dwyer R, Najm I, Alexopoulos A, W. B. A longitudinal study of surgical outcome and its determinants following posterior cortex epilepsy surgery. Epilepsia. 2009;50(9):2040-2052.

26. Jianguo Shi J, Gaoc Z, Gaob J, Li G, Chenc Y. Predictors and outcome surgery for posterior cortex epilepsies. Clinical Neurology and Neurosurgery 2018 Jun;171: 124-128.
27. Engel J. What can we do for people with drug-resistant epilepsy? The 2016 Wartenberg Lecture. Neurology 2016 Dic, 87(23), 2483-2489.

28. Kudr M, Krsek P, Maton B, Malone S, Jahodova A, Komarek V, Jayakar P, Duchowny M. Ictal SPECT is useful in localizing the epileptogenic zone in infants with cortical dysplasia. Epileptic Disord. 2016 Dec 1;18(4):384-390.

29. Harward E, Chen W, Rolston J, Haglund M, Englot D. Seizure Outcomes in Occipital Lobe and Posterior Quadrant Epilepsy Surgery: A Systematic Review and Meta-Analysis. Neurosurgery 2018 Mar; 82(3): 350-358.

30. Kim D; Lee S, Ki-Young Jung K. Surgical Treatment of Non lesional Neocortical Epilepsy Long-term Longitudinal Study. JAMA Neurol. 2017 Mar;74(3):324-331.

31. Hussain SA, Mathern G, Hung P, Weng J, Sankar R, Wu J. Intraoperative fast ripples independently predict postsurgical epilepsy outcome: Comparison with other electrocorticographic phenomena.Epilepsy Res. 2017 September ; 135: 79-86.

32. Wook Kim D, Kun Lee S, Moon H, Jung,K, Chu K, Chung C, et al. Surgical treatment of non lesional neocortical epilepsy long-term longitudinal study. JAMA Neurol. 2017;74(3):324331.

33. Shan X, Fan X, Liu X, Zhao Z, Wang Y, Jiang T. Clinical characteristics associated with postoperative seizure control in adult low-grade gliomas: a systematic review and metaanalysis. Neuro Oncol. 2018 Feb 19;20(3):324-331.

34. Faramand A, Barnes N, Harrison S, Gunny R, Jacques T, Tahir $\mathrm{Z}$, et al. Seizure and cognitive outcomes after resection of glioneuronal tumors in children. Epilepsia. 2018 Jan;59 (1): $170-178$.

35. Widjaja E, Jain P, Demoe L, Guttmann A, Tomlinson G, Sander B. Seizure outcome of pediatric epilepsy surgery Systematic review and meta-analyses Neurology 2020;94:311321.

36. Chen X, Huang C, Zhu H, Yang H. Predictors of seizure recurrence in patients with surgery for focal cortical dysplasia: pairwise and network meta-analysis and trial sequential analysis. Child's Nervous System. 2019. April;35(5): 757-767.

37. Pilipovi S, Risti A, Bukumiri Z, Trajkovi G, Soki D. Long-term seizure outcome following parietal lobe epilepsy surgery: a meta-analysis. Epileptic Disord 2018 April; 20 (2): 116-122.

38. Arya R, Leach J, Horn P, Greiner H, Gelfand M, Byars A, et al. Clinical factors predict surgical outcomes in pediatric MRInegative drug-resistant epilepsy. Seizure 2016;41 56-61.

39. Jehi L, Yehia L, Peterson Ch, Niazi F, Busch R, Prayson R, et al. Preliminary report: Late seizure recurrence years after epilepsy surgery may be associated with alterations in brain tissue transcriptome. Epilpesia open.2018; 3(2):299-304. 
(c) (

This work is licensed under Creative

Commons Attribution 4.0 License

To Submit Your Article Click Here: Submit Manuscript

DOI: $10.31579 / 2578-8868 / 196$
Ready to submit your research? Choose Auctores and benefit from:

* fast, convenient online submission

* rigorous peer review by experienced research in your field

* rapid publication on acceptance

* authors retain copyrights

* unique DOI for all articles

* immediate, unrestricted online access

At Auctores, research is always in progress.

Learn more https://auctoresonline.org/journals/neuroscience-andneurological-surgery 